\title{
BMJ Global Health Safe management of bodies of deceased persons with suspected or confirmed COVID-19: a rapid systematic review
}

Sally Yaacoub (D) , ${ }^{1}$ Holger J Schünemann, ${ }^{2,3}$ Joanne Khabsa (D) ,1 Amena El-Harakeh, ${ }^{1}$ Assem M Khamis (D , , ${ }^{4}$ Fatimah Chamseddine, ${ }^{1}$ Rayane El Khoury, ${ }^{1}$ Zahra Saad, ${ }^{5}$ Layal Hneiny, ${ }^{6}$ Carlos Cuello Garcia, ${ }^{7}$ Giovanna Elsa Ute Muti-Schünemann, ${ }^{8}$ Antonio Bognanni, ${ }^{7}$ Chen Chen, ${ }^{9}$ Guang Chen, ${ }^{10}$ Yuan Zhang, ${ }^{7}$ Hong Zhao, ${ }^{11}$ Pierre Abi Hanna, ${ }^{12}$ Mark Loeb, ${ }^{13}$ Thomas Piggott, ${ }^{7}$ Marge Reinap, ${ }^{14}$ Nesrine Rizk, ${ }^{15}$ Rosa Stalteri, ${ }^{7}$ Stephanie Duda, ${ }^{7}$ Karla Solo (D) , ${ }^{7}$ Derek K Chu (D) , ${ }^{7}$ Elie A Akl, ${ }^{1,7,16}$ the COVID-19 Systematic Urgent Reviews Group Effort (SURGE) group

To cite: Yaacoub S, Schünemann HJ, Khabsa J, et al. Safe management of bodies of deceased persons with suspected or confirmed COVID-19: a rapid systematic review. BMJ Global Health 2020;5:e002650. doi:10.1136/ bmjgh-2020-002650

Handling editor Soumyadeep Bhaumik

- Additional material is published online only. To view please visit the journal online (http://dx.doi.org/10.1136/ bmjgh-2020-002650).

Received 14 April 2020 Revised 22 April 2020 Accepted 23 April 2020

Check for updates

\section{(C) Author(s) (or their} employer(s)) 2020. Re-use permitted under CC BY. Published by BMJ.

For numbered affiliations see end of article.

\section{Correspondence to}

Dr Elie A Akl; ea32@aub.edu.lb

\section{ABSTRACT}

Introduction Proper strategies to minimise the risk of infection in individuals handling the bodies of deceased persons infected with 2019 novel coronavirus (2019-nCoV) are urgently needed. The objective of this study was to systematically review the literature to scope and assess the effects of specific strategies for the management of the bodies.

Methods We searched five general, three Chinese and four coronavirus disease (COVID-19)-specific electronic databases. We searched registries of clinical trials, websites of governmental and other relevant organisations, reference lists of the included papers and relevant systematic reviews, and Epistemonikos for relevant systematic reviews. We included guidance documents providing practical advice on the handling of bodies of deceased persons with suspected or confirmed COVID-19. Then, we sought primary evidence of any study design reporting on the efficacy and safety of the identified strategies in coronaviruses. We included evidence relevant to contextual factors (ie, acceptability). A single reviewer extracted data using a pilot-tested form and graded the certainty of the evidence using the GRADE approach. A second reviewer verified the data and assessments.

Results We identified one study proposing an uncommon strategy for autopsies for patients with severe acute respiratory syndrome. The study provided very low-certainty evidence that it reduced the risk of transmission. We identified 23 guidance documents providing practical advice on the steps of handling the bodies: preparation, packing, and others and advice related to both the handling of the dead bodies and the use of personal protective equipment by individuals handling them. We did not identify COVID-19 evidence relevant to any of these steps.

Conclusion While a substantive number of guidance documents propose specific strategies, we identified no study providing direct evidence for the effects of any of those strategies. While this review highlights major research gaps, it allows interested entities to build their own guidance.

\section{Summary box}

What is already known?

- There is scarce evidence on the transmission of coronavirus disease 2019 (COVID-19) and othe coronaviruses from the dead bodies of confirmed or suspected cases.

- There are uncertainties about how to handle the bodies of deceased persons with confirmed or suspected COVID-19.

What are the new findings?

- The main findings of this review are based on guidance documents as opposed to primary studies.

- We identified one eligible study that evaluated a biosafety level 3 laboratory for autopsies of patients with SARS.

- We summarised the steps from 23 guidance documents providing practical advice on the steps of handling the bodies and the use of personal protective equipment by individuals handling them.

What do the new findings imply?

- WHO will use the findings of this study to inform its response to the COVID-19 pandemic.

- The interpretation of the findings needs to consider that the included guidance are not supported by direct evidence.

- There are additional research questions on the modes of transmission of COVID-19 from dead bodies to individuals, the desirable and undesirable effects of each management strategy, and contextual factors that require evidence.

\section{INTRODUCTION}

On 11 March, WHO characterised the 2019 novel coronavirus (2019-nCoV) outbreak as a pandemic. On 20 April 2020, the pandemic had affected more than 2400000 individuals 


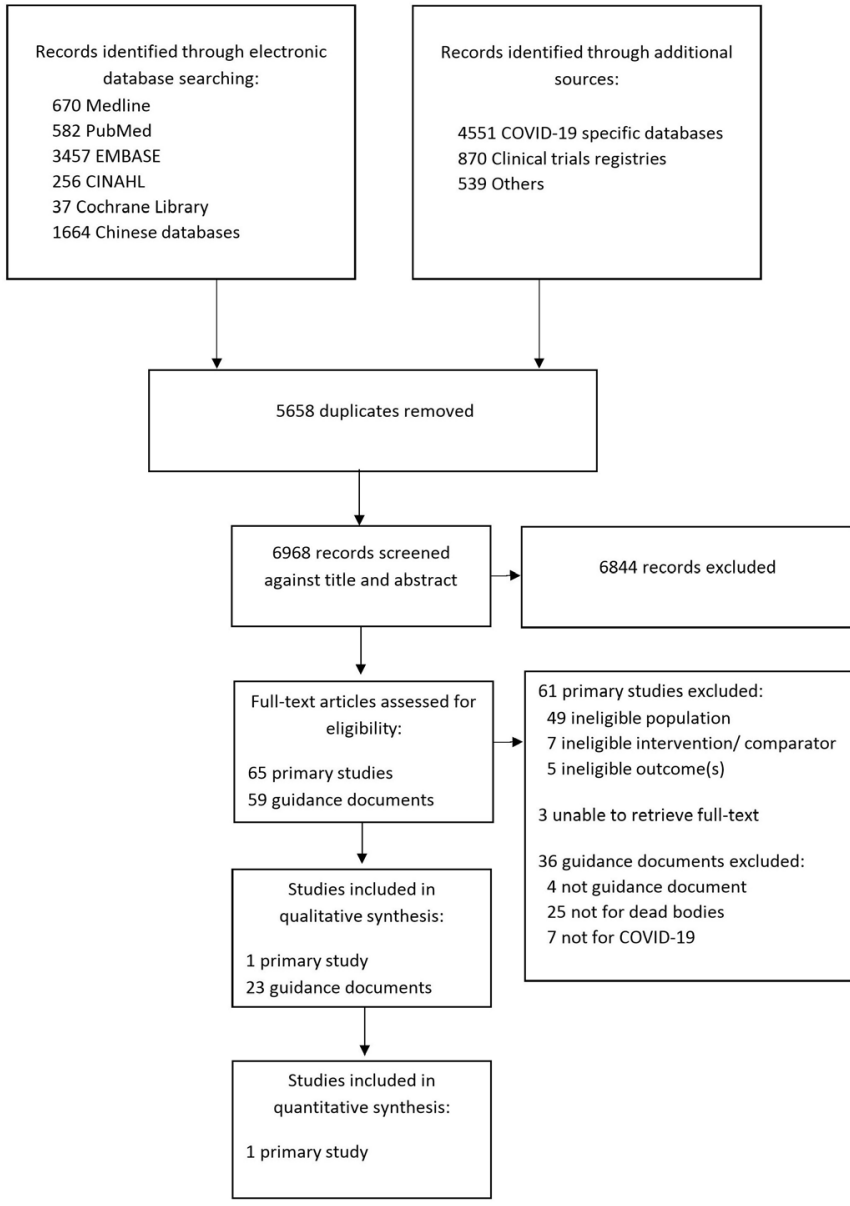

Figure 1 Study selection.

worldwide. Over the same time period, it has claimed the lives of 165000 individuals. ${ }^{1}$ More concerning than the absolute number of deaths is their rate of increase.

The severe acute respiratory syndrome coronavirus 2 (SARS-CoV-2), which causes the coronavirus disease 2019 (COVID-19), has been characterised as highly contagious, with a relatively high case fatality rate, compared with other viral respiratory infections. This has created anxiety about the preparation and the burial of the bodies of deceased persons with suspected or confirmed COVID-19. There appears to be scarce evidence on the transmission of COVID-19 and other coronaviruses from the dead bodies of confirmed or suspected cases. In one study, Liu et al reported that $27.8 \%$ of healthcare workers in contact with deceased cases of severe acute respiratory syndrome (SARS) contracted the coronavirus. ${ }^{2}$ In another study, Mahallawi reported a case of Middle East respiratory syndrome (MERS) coronavirus in nasal secretions of a dead case. ${ }^{3}$ Similarly, there is confusion about how to safely perform autopsies on those bodies. Considering these uncertainties about how to handle the bodies of deceased persons with confirmed or suspected COVID-19 cases, answers to these questions are on the priority list for WHO.

Individuals at risk include healthcare workers, morgue staff, transport staff, family members, crematories staff, burial staff and religious staff. It is also a cultural challenge, as some cultural aspects and religious practices may influence how the bodies are handled and the associated risk of transmission. Moreover, the acceptability of different management strategies might vary across cultural and religious groups.

The objective of this study was to systematically review the literature to first scope, and then assess the effects of, specific strategies for the management of the bodies of deceased persons with suspected or confirmed COVID19. We conducted a rapid systematic review, commissioned by WHO, to be able to inform their response to COVID-19 pandemic.

\section{METHODS}

The protocol was submitted to PROSPERO; however, it was not accepted because of the scoping component. We have registered the protocol in Open Science Framework (https://osf.io/j3nft).

\section{Search strategy and selection criteria}

We conducted a rapid systematic review to identify, select, abstract, assess, and synthesise the available evidence addressing our question of interest. ${ }^{4}$

We developed the search strategy with the assistance of an information specialist experienced with systematic reviews (LH). Two information specialists peer reviewed the search strategy. Other members of the team, particularly the content experts, provided feedback to the search strategy. An additional search strategy was developed to identify indirect evidence from systematic reviews on SARS and MERS. We searched the following general electronic databases: Medline (using OVID platform), PubMed, EMBASE, CINAHL (using OVID platform) and the Cochrane Library. We also searched COVID-19specific electronic databases such as COVID-19 Open Research Dataset (CORD-19), COVID-19 Research Database maintained by WHO (including its daily updates), Epistemonikos COVID-19 L.OVE platform and EPPI Centre living systematic map of the evidence. In addition, we searched Chinese databases such as WHO Chinese database, CNKI and China Biomedical Literature Service. Online supplementary appendix 1 includes the search strategies for the different general databases. The search strategies combined medical subject headings (MeSH) and keywords for the two following concepts: COVID-19 and dead bodies. PubMed search terms were informed by the Biomedical Information of the Dutch Library Association specialists curated search blocks. ${ }^{5}$ The related searches covered the date range from inception to 26 March 2020. We used no language restrictions.

Additional searches included searching for registered clinical trials in both the U.S. National Library of Medicine Register of Clinical Trials (ClinicalTrials.gov) and the WHO International Clinical Trials Registry Platform, searching for relevant documents on the websites of governmental and other relevant organisations, 
Table 1 Characteristics of the included study

\begin{tabular}{|c|c|c|c|c|c|c|c|}
\hline Study & Population & $\begin{array}{l}\text { Study } \\
\text { type }\end{array}$ & Setting & $\begin{array}{l}\text { Intervention and } \\
\text { comparator }\end{array}$ & Comparator & Outcomes & $\begin{array}{l}\text { Risk of } \\
\text { bias/quality }\end{array}$ \\
\hline $\begin{array}{l}\text { Li et al } \\
(2005)^{10}\end{array}$ & $\begin{array}{l}23 \text { pathologists } \\
\text { and technicians } \\
\text { performed } 16 \\
\text { autopsies }\end{array}$ & $\begin{array}{l}\text { Case } \\
\text { study }\end{array}$ & $\begin{array}{l}\text { Autopsy } \\
\text { laboratory } \\
\text { in China }\end{array}$ & $\begin{array}{l}\text { Multicomponent } \\
\text { intervention: } \\
\text { construction, } \\
\text { PPE, disposal } \\
\text { and other } \\
\text { measures } \\
\text { components }\end{array}$ & $\begin{array}{l}\text { No } \\
\text { comparator } \\
\text { group }\end{array}$ & $\begin{array}{l}\text { Infections: } \\
\text { Proportion of infections: } 0 / 23 \\
\text { Evaluation of decontamination measured by } \\
\text { sarin simulant test: in the contaminated area, } \\
\text { sarin concentration decreased from } 10 \text { to } 2 \mathrm{ppm} \\
\text { to } 0 \mathrm{ppm} \text {, and sarin was undetectable in the } \\
\text { clean area and the semi-contaminated area }\end{array}$ & $\begin{array}{l}\text { High risk of } \\
\text { bias }\end{array}$ \\
\hline
\end{tabular}

screening reference lists of the included papers and relevant systematic reviews, and searching Epistemonikos for relevant systematic reviews addressing SARS and MERS.

We included studies meeting specific criteria for the population, interventions, comparisons and outcomes of interest. Our populations of interest included the bodies of deceased persons with suspected or confirmed COVID-19, and the individuals handling those bodies, including nursing and medical personnel, morgue staff, transport staff, family members, crematories staff, burial staff and religious staff. In addition, and as a source of indirect evidence for primary studies, we considered primary studies and systematic reviews about the bodies of deceased persons with suspected or confirmed infections with either SARS virus or the MERS virus, as well as the individuals handling those bodies. The interventions of interest included any strategy to manage bodies of deceased persons, during the different phases of the process. These strategies would address either the bodies themselves or the individuals handling them. The outcomes of interest included risk of COVID-19 transmission to the individuals handling the bodies and to members of the community, morbidity and mortality associated with COVID-19, unintended harms of the management strategies, acceptability by different stakeholders (family members of the deceased person, members of the community, individuals handling the dead bodies, health authorities), and surrogate outcomes such as contact or droplet transmission. Also eligible were studies providing evidence relevant to contextual factors such as acceptability, feasibility, impact on equity and resources considerations related to the interventions of interest.

We included any study design including randomised controlled trials, non-randomised studies (including cohort studies, case-control studies, case series and case reports) and qualitative studies. In addition, we included guidance documents on the handling of bodies of deceased persons with suspected or confirmed COVID-19 identified from the websites of relevant organisations and national authorities by content experts and peer-reviewed literature.

\section{Study selection}

We exported the literature search results to EndNote X9 for de-duplication, then to Covidence software. All reviewers pilot-tested a standardised title and abstract screening form using the same 30 citations. Once the form was calibrated, the reviewers screened in duplicate and independently all titles and abstracts using above listed eligibility criteria. We obtained the full texts for citations judged as potentially eligible by either reviewer.

All reviewers pilot-tested a full-text screening form using the same five full-text articles. Once the form was calibrated, the reviewers screened the full texts independently and in duplicate and resolved any conflicts by discussion, or with the help of a third reviewer. We recorded the primary reason for exclusion at the full-text screening stage.

\section{Data extraction}

We developed and piloted with all reviewers a standardised data abstraction form in Excel.

Two independent reviewers extracted data using that form. We extracted data about the following: study identifier; study design; setting; population characteristics; intervention and comparator characteristics; outcomes (quantitative if possible); source of funding and reported conflicts of interests; ethical approval; study limitations or other important comments. For the identified guidance documents, a single reviewer extracted data and a second reviewer verified the extracted data. We extracted data about the publishing organisation and country, whether the documents were dedicated to COVID-19 dead bodies management, as well as specific guidance under each step of the process. We also extracted information on personal protective equipment (PPE).

\section{Risk of bias assessment}

One reviewer was to perform the risk of bias assessment and a second reviewer would verify all assessments. We planned to use the Newcastle-Ottawa scale for nonrandomised studies.

\section{Synthesis}

We synthesised the data in both narrative and tabular formats. A single reviewer graded the certainty of the evidence using the GRADE approach and a second reviewer verified all assessments. ${ }^{6}$ When applicable, we followed published guidance for rating the certainty in evidence in the absence of a single estimate of effect. ${ }^{7}$ We present the evidence using GRADE Evidence Profiles developed in the GRADEpro (www.gradepro.org) software. $^{89}$ 


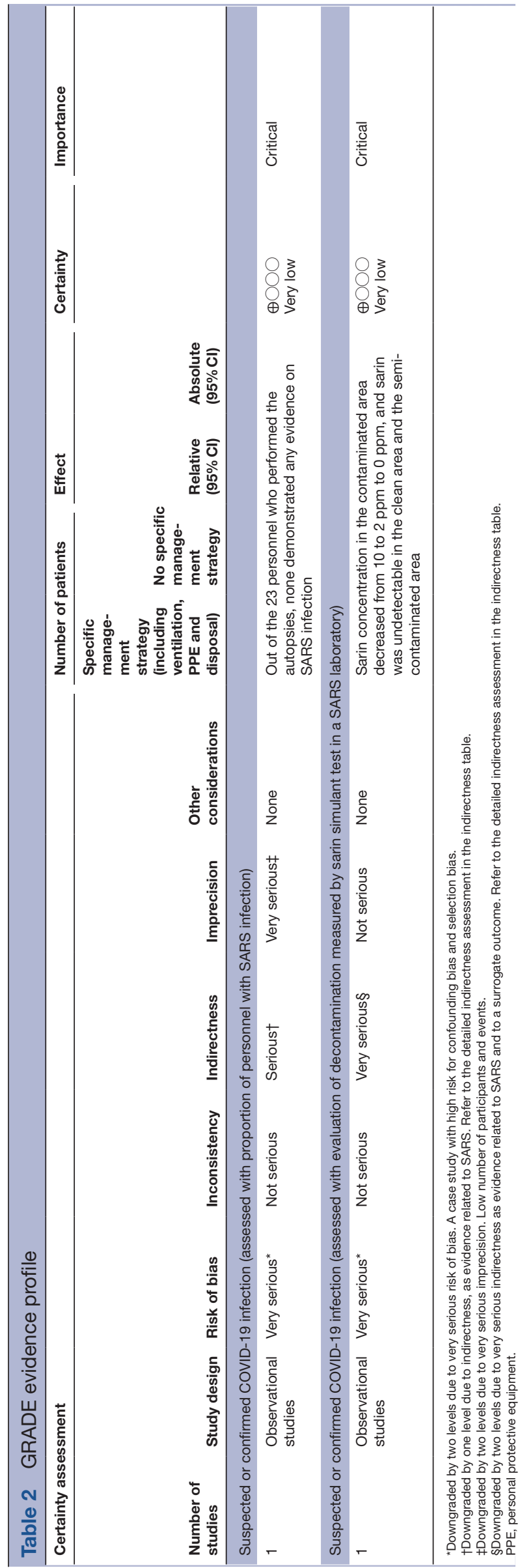

RESULTS

\section{Results of the selection process}

Figure 1 shows the study selection represented in a PRISMA flow chart. We identified 23 guidance documents specific to COVID-19. We did not identify any study providing direct evidence related to COVID-19 (whether on health effects or for contextual evidence). We identified one eligible study that evaluated a biosafety level 3 (BSL-3) laboratory for autopsies of patients with SARS. ${ }^{10}$ We did not identify any relevant systematic review on SARS or MERS.

\section{Summary of direct empirical findings}

Table 1 describes the characteristics of the one included study. ${ }^{10}$ In summary, it was a non-comparative study conducted in a BSL-3 laboratory for autopsies of clinically confirmed or suspected SARS infections in China. It included 16 autopsies performed by 23 pathologists and technicians. The intervention was a complex intervention with components including construction, PPE and disposal. In terms of findings, the authors reported that none of the 23 involved individuals was diagnosed with a SARS infection. In addition, the investigators used the sarin simulant test to assess decontamination. Sarin concentration decreased from 10 to $2 \mathrm{ppm}$ to $0 \mathrm{ppm}$ in the contaminated area and was undetectable in the clean area and the semi-contaminated area.

We report the evidence profile in table 2. We judged the certainty of evidence as very low, mainly due to very serious risk of bias, and very serious imprecision.

\section{Summary of the guidance documents}

We identified 23 guidance documents providing practical advice on handling suspected or confirmed cases of COVID-19 corpses throughout the different phases. We have summarised the content of these documents in three tables in online supplementary appendix 2 .

Table 3 shows the characteristics of the 23 included guidance documents on the strategies for the management of dead bodies of confirmed or suspected COVID-19 cases.

The majority of the documents were published in English $(n=18,78 \%)$. Eight of the 23 documents (35\%) were entirely dedicated to handling of COVID-19 dead bodies. Most of the documents specified that bodies were for suspected or confirmed COVID-19 corpses $(n=18$, $78 \%$ ). Settings most commonly addressed in those documents were the hospitals $(n=12,52 \%)$, healthcare facilities $(\mathrm{n}=4,17 \%)$ and communities $(\mathrm{n}=3,13 \%)$.

Online supplementary appendix 2 table A synthesises, across the included guidance documents, the strategies for the management of the bodies of deceased persons with suspected or confirmed COVID-19. The strategies include one or more of the following steps: body preparation (includes healthcare setting and non-healthcare setting), packing, transport to storage site, storage site, viewing, embalming, burial, cremation and other measures. Five documents out of the 23 (22\%) report taking into consideration factors related 


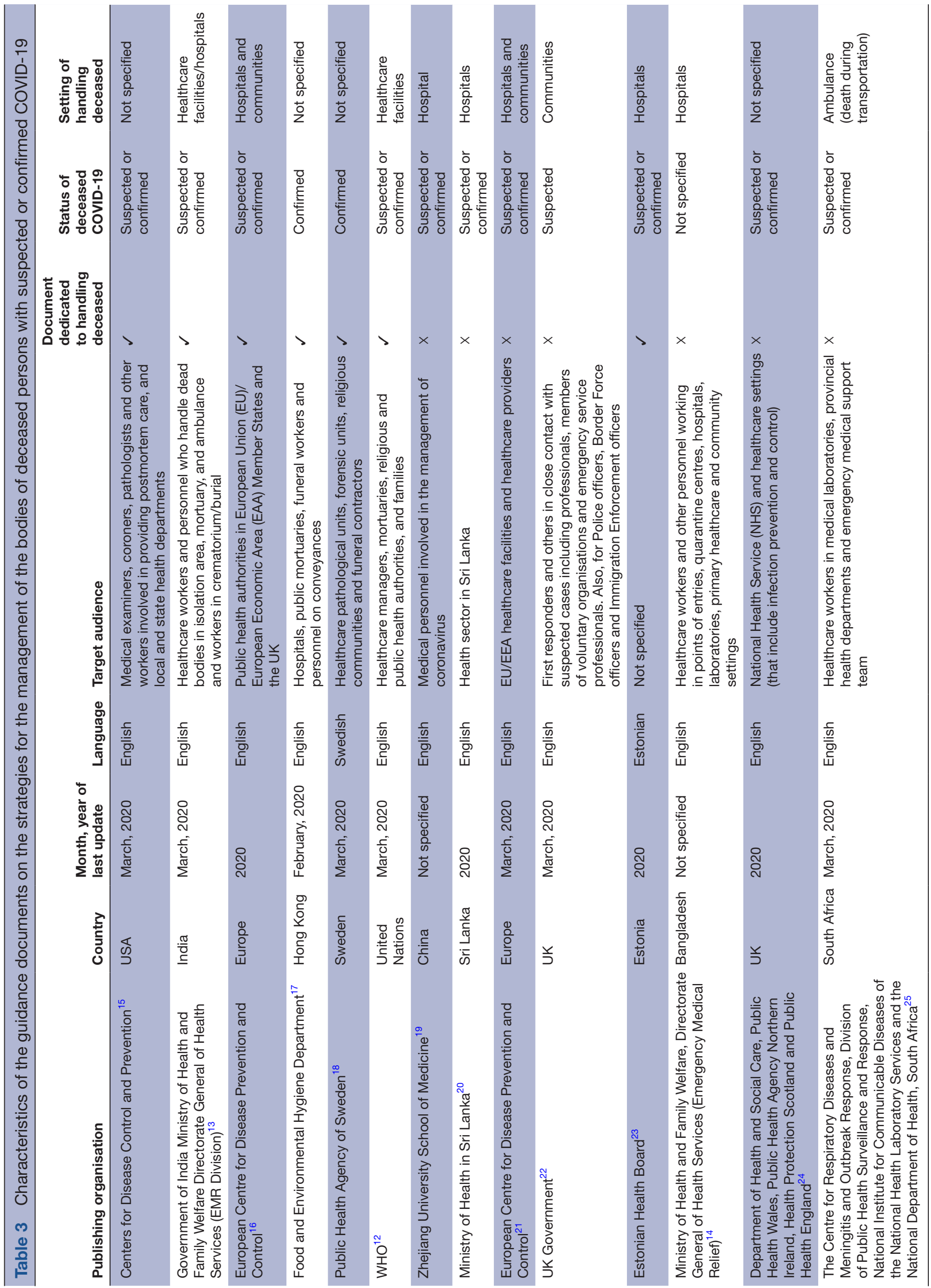

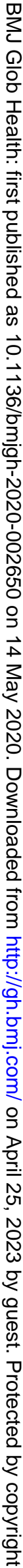




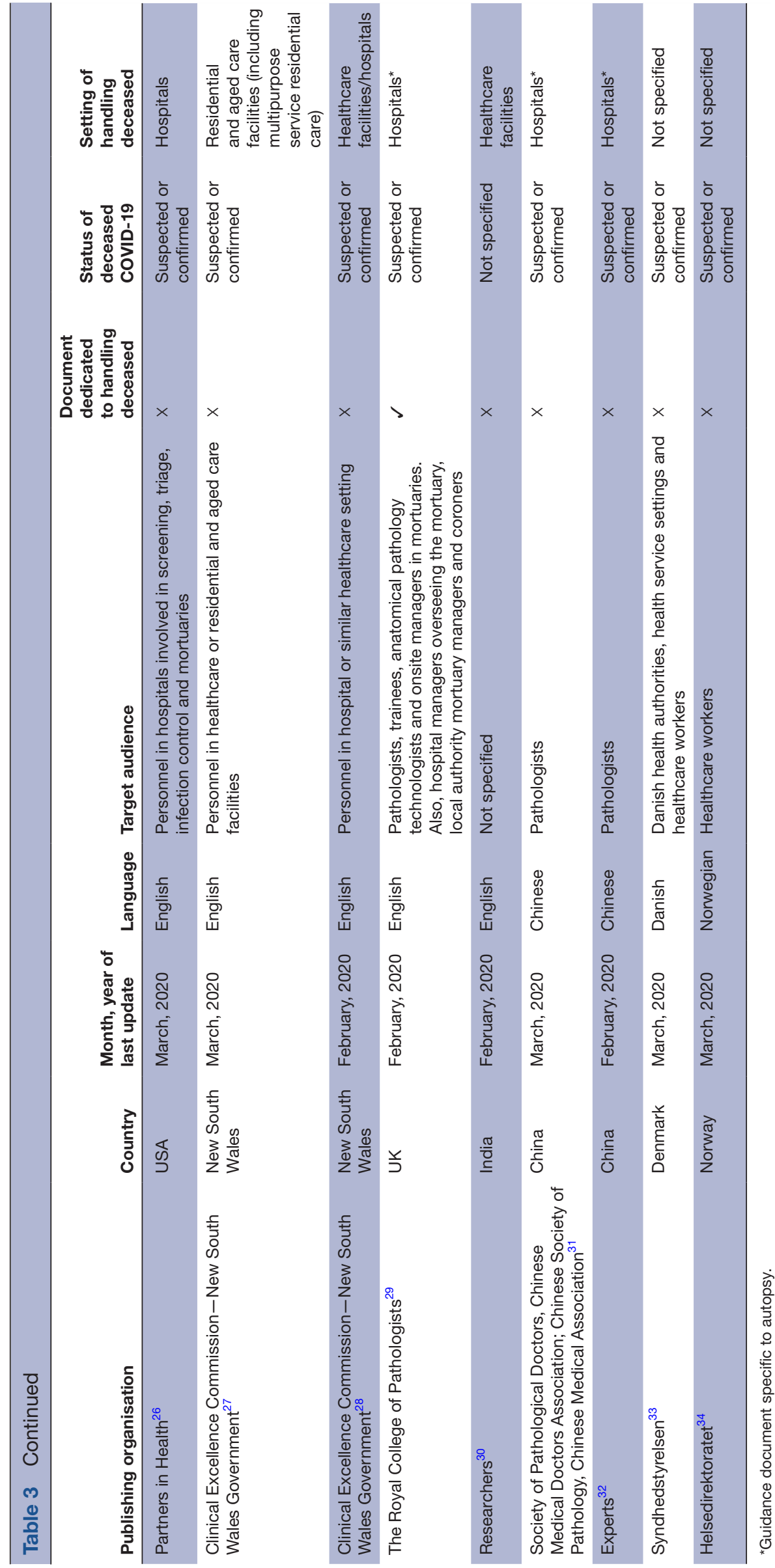

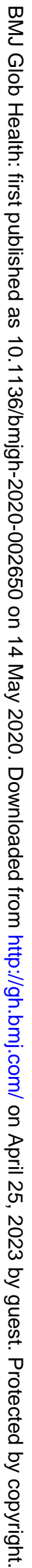


to the context when applying the recommendations provided. These include cultural, religious and familial factors. Out of the five documents, two specify taking these factors into account for all the recommendations, whereas the remaining are specific to cremation $(n=2)$ (online supplementary appendix 2 table A) and autopsies $(n=1)$ (online supplementary appendix 2 table $\mathrm{C}$ ). Figure 2 represents an infographic summarising the steps reported in the guidance documents. Online supplementary appendix 3 includes the same infogrpahic in the following languages: Arabic, French, German, Italian and Portugese. The expanded version of the infographic is in the online supplementary appendix 1.

Online supplementary appendix 2 table B consists of a matrix indicating what PPE was recommended for use in each of the steps of the management of the bodies of deceased persons with suspected or confirmed COVID-19.

Online supplementary appendix 2 table $\mathrm{C}$ provides the recommendations in the guidance documents for performing autopsies on the bodies of deceased persons with suspected or confirmed COVID-19. The main elements are the indications to perform autopsies, the physical environment and disinfection, the professionals involved and limitations on individuals involved.

\section{DISCUSSION}

\section{Summary of findings}

In summary, we did not identify any direct evidence relating to the effects of specific strategies for the management of the bodies of deceased persons with suspected or confirmed COVID-19. Even when expanding to consider indirect evidence, we found scarce literature relating to SARS and MERS infections. The one study we identified provides very low certainty evidence that the specific approach used by $\mathrm{Li}$ et al to set up the autopsy laboratory reduced the risk of transmission to the personnel handing dead bodies. ${ }^{10}$

\section{Strengths and limitations}

This review has a number of strengths. First, we searched for indirect evidence relating to two other coronaviruses that are similarly dangerous to COVID-19, that is, SARS and MERS. Second, we used a very comprehensive search of both the indexed and grey literatures, with no restrictions to specific languages or study design. Third, and despite the short timeline for conducting the review (7 days), we were able to use a standard systematic review methodology for the primary studies, that is, without any shortcuts sometimes used in rapid reviews. We were able to achieve this through the involvement of a large and experienced systematic review team. One limitation of our study is that we did not use a duplicate approach for data extraction and synthesis for the guidance documents.

\section{Interpretation of findings}

The primary evidence was limited only to management of autopsies and does not cover the main steps of handling of dead bodies. Also, the availability of BSL-3 laboratories and autopsy rooms may be a barrier in many settings, especially for low-resources settings.

The guidance documents proved to be very useful in identifying discrete steps in the management of bodies of deceased persons with suspected or confirmed COVID19 . We noted some variability in the strategies adopted for the different steps across these documents. One limitation of the guidance documents is the lack of consideration of cultural practices around death (eg, cremation vs burial, peri-cremation/burial practices, cultural preferences). Still, and given the lack of primary research, these documents can be helpful to governmental or nongovernmental entities when developing such guidance.

\section{Implications for public health practice}

There might be significant harms from the transmission of COVID-19 from the bodies of deceased persons considering the number of deaths currently observed and anticipated in the COVID-19 pandemic. There is one report on a forensic practitioner in Thailand who had contact with biological samples and corpses of COVID-19 and contracted the virus. ${ }^{11}$ This systematic review showed that gaps exist in the evidence base for different management strategies of the bodies of deceased persons for coronaviruses in general, and COVID-19 in particular.

In the absence of such evidence, the synthesis of guidance documents, provided in online supplementary appendix 2, could inform public health protocols around the handling of dead bodies. For example, the current interim WHO guidance draws on evidence from other respiratory viruses including pandemic influenza. ${ }^{12}$ Given gaps in direct evidence on COVID-19, the findings continue to be relevant. However, the interpretation of these findings needs to consider that the included guidance are not supported by direct evidence.

While the risk of infection from dead bodies is deemed to be low, a precautionary approach using PPE including gloves, gown, mask and goggles would be reasonable where direct contact with dead bodies or fluid spray from dead bodies is possible. Only two guidance documents recommended the use of $\mathrm{N} 95$ respirators for the handling of dead bodies. ${ }^{13} 14$ Given the absence of direct research evidence, any recommendations on PPE use for handling bodies of deceased people in different settings must balance the uncertainty of the benefits and harms with feasibility considerations, such as PPE stock and availability.

\section{Implications for research}

There are three types of related questions that require research evidence. First, there is a need for evidence on the modes of transmission of COVID-19 from bodies of deceased persons to the different types of individuals handling those bodies. Such evidence is essential to propose potentially effective management strategies. Second, there is a need for evidence on the desirable and undesirable health effects and other consequences 


\section{Safe Management of Bodies of Deceased Persons with Suspected or Confirmed COVID-19}

Rapid Systematic Review

\section{STEPS HANDLING OF \\ ADDRESSED DEAD BODY}

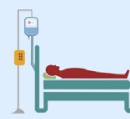

BODY PREPARATION

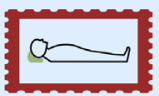

PACKING

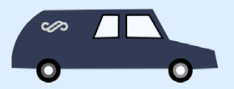

TRANSPORT TO STORAGE SITE

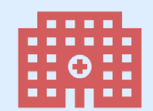

STORAGE SITE

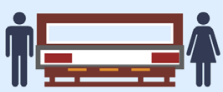

VIEWING

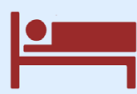

EMBALMING

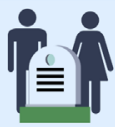

BURIAL

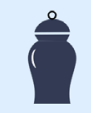

CREMATION

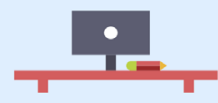

PLANNING

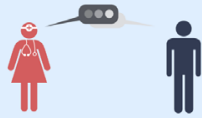

OTHER required. human remains. body. body. procedures.

standard practice.
Remove IV tubes and lines.

Disinfect puncture holes.

Disinfect surfaces where body was resting

Manage as a specific risk category.

Universal precautions of material used.

Two-layer cover of the body using leak-proof bag

Disinfect outer packing.

Standard local routine procedure. No special transport

Decontaminate vehicle and minimize contact with

If moving to another country check restrictions on importing bodies with confirmed/suspected COVID-19.

Should remain clean and disinfected.

Facility properly ventilated and illuminated.

Cold chambers at $4^{\circ} \mathrm{C}$.

Practice safe waste disposal.

Only by close relatives in a pre-designated area. Use standard precautions to allow viewing of the

Provide support in appropriate PPE use for mourners. Advise mourners not to touch the body.

Mostly not recommended. If performed, use standard precautions and protective measures, and only by trained personnel.

Can be performed regularly. Sensitize burial staff about COVID-19 and standard precautions. Religious rituals allowed as long as there is no contact with the

Can be performed if facilities are available. Cremate within 24 hours without taking the body home.

Sensitize staff. Relatives can view dust. Follow local

Establish preparedness plan for handling dead bodies, access to trained staff, transport, equipment, and body storage. Review national contingency plans and communicate.

Consult with stakeholders (e.g. religious

representatives) to ensure acceptability of changes to

Provide counselling to family members.

\section{PPE OF INDIVIDUALS HANDLING DEAD BODIES}

Gloves, long-sleeved water resistant gown, mask, goggles, limit direct personnel involvement.

Full complement of PPE (e.g. gloves and long-sleeved water-resistant gown).

Gloves, disposable nitrile gloves, surgical mask, triple layer medical mask, long-sleeved water-resistant gown.

Direct contact with human remains or bodily fluids should be minimized during reception at designated body storage sites. Strict PPE procedures (e.g., gloves, gown, long-sleeved water-resistant gown, hand hygiene, goggles/face shield, mask). No aerosol generating procedures should be allowed.

PPE is not needed for relative viewing, yet, they should limit any contac with the body. If relatives have touched the body, use recommended hygiene procedures.

Hand hygiene and standard PPE (e.g., gloves and long-sleeved water resistant gown) if the procedure is allowed.

The minimum requirements include gloves and long-sleeved waterresistant gown for staff.

Avoid any crowding during funeral services, and advice participants to maintain physical distancing and hand hygiene.

Follow protective measures and standard precautions.

Avoid any crowding at crematorium ground.

Assess the need for PPE in healthcare professionals and the need for training on its use.

Figure 2 Infographic illustrating the different steps in the management of bodies of deceased person with suspected or confirmed COVID-19. PPE, personal protective equipment. 
of proposed management strategies. Third, there is a need for contextual evidence in relation to these proposed management strategies (ie, acceptability, feasibility, impact on equity, resources considerations). Such evidence is extremely important given the cultural and religious dimensions of the handling of bodies of deceased patients.

\section{Author affiliations}

${ }^{1}$ Clinical Research Institute, American University of Beirut, Beirut, Lebanon ${ }^{2}$ WHO Collaborating Centre for Infectious Diseases, McMaster University, Hamilton, Ontario, Canada

${ }^{3}$ Research Methods and Recommendations and the Michael G. DeGroote Cochrane Canada and McGRADE Centres, McMaster University, Hamilton, Ontario, Canada

${ }^{4}$ Hull York Medical School, University of Hull, Hull, UK

${ }^{5}$ Global Evidence Synthesis Initiative, American University of Beirut, Beirut, Lebanon ${ }^{6}$ University Libraries, Saab Medical Library, American University of Beirut, Beirut, Lebanon

${ }^{7}$ Department of Health Research Methods, Evidence and Impact, McMaster University, Hamilton, Ontario, Canada

${ }^{8}$ Medical School, Vita Salute San Raffaele University, Milano, Italy

${ }^{9}$ Guangzhou University of Chinese Medicine, The Fourth Clinical Medical College, Guangdong, China

${ }^{10}$ Beijing University of Chinese Medicine, Dongzhimen Hospital, Beijing, China

${ }^{11}$ Institute of Acupuncture and Moxibustion, China Academy of Chinese Medical Sciences, Beijing, China

${ }^{12}$ Infectious Disease Division, Rafik Hariri University Hospital, Beirut, Lebanon ${ }^{13}$ Department of Pathology and Molecular Medicine, McMaster University, Hamilton, Ontario, Canada

${ }^{14}$ London School of Hygiene and Tropical Medicine, London, UK

${ }^{15}$ Division of Infectious Diseases, American University of Beirut, Beirut, Lebanon

${ }^{16}$ Department of Internal Medicine, American University of Beirut, Beirut, Lebanon

Acknowledgements We would like to thank Ms Aida Farha and Ms Neera Bhatnagar for peer reviewing the search strategy, Dr Yuqing (Madison) Zhang for assistance with Chinese literature, Dr Finn Schünemann for helping with screening, and Dr Susan L Norris and Dr April Baller for their input on the protocol. DKC is a CAAIF-CSACI-AllerGen Emerging Clinician-Scientist Research Fellow, supported by the Canadian Allergy, Asthma and Immunology Foundation (CAAIF), the Canadian Society of Allergy and Clinical Immunology (CSACI) and AllerGen NCE Inc. (the Allergy, Genes and Environment Network). This systematic review was commissioned and (in part) paid for by the World Health Organization. The authors alone are responsible for the views expressed in this article and they do not necessarily represent the decisions, policy or views of the World Health Organization.

Contributors EAA and HJS conceived the study. EAA, HJS, SY, DKC, SD, KS, PAH, ML and NR designed the study. SY, SD, and KS coordinated the study. SY and LH designed and ran the search. MR, NR and RS searched the grey literature for guidance documents. SY, JK, AE-H, AMK, FC, ZS, REK, LH, CC, GC, $\mathrm{YZ}$ and $\mathrm{HZ}$ assessed eligibility and abstracted data. GEUM-S, AB, PAH, MR and HJS assessed eligibility. EAA, HJS, SY, JK and AE-H analysed and interpreted the data. CCG summarised data and developed the infographics. SY and EAA drafted the manuscript. HJS and TP contributed to writing the manuscript. All authors contributed to the interpretation and subsequent edits of the manuscript. EAA attests that all listed authors meet authorship criteria and that no others meeting the criteria have been omitted.

Funding The funding of this article was provided by the World Health Organization, American University of Beirut, and McMaster University.

Competing interests None declared.

Patient and public involvement Patients and/or the public were not involved in the design, or conduct, or reporting, or dissemination plans of this research.

Patient consent for publication Not required.

Provenance and peer review Not commissioned; internally peer reviewed.

Data availability statement Data are available on request to the corresponding author.
Open access This is an open access article distributed in accordance with the Creative Commons Attribution 4.0 Unported (CC BY 4.0) license, which permits others to copy, redistribute, remix, transform and build upon this work for any purpose, provided the original work is properly cited, a link to the licence is given, and indication of whether changes were made. See: https://creativecommons.org/ licenses/by/4.0/.

\section{ORCID iDs}

Sally Yaacoub http://orcid.org/0000-0003-0819-1561

Joanne Khabsa http://orcid.org/0000-0002-4336-3501

Assem M Khamis http://orcid.org/0000-0002-5567-7065

Karla Solo http://orcid.org/0000-0001-6134-9140

Derek K Chu http://orcid.org/0000-0001-8269-4496

\section{REFERENCES}

1 Center for Systems Science and Engineering at Johns Hopkins University. Coronavirus COVID-19 global cases, 2019. Available: https://coronavirus.jhu.edu/map.html

2 Liu W, Tang F, Fang L-Q, et al. Risk factors for SARS infection among hospital healthcare workers in Beijing: a case control study. A European J TMIH 2009;14:52-9.

3 Mahallawi WH. Case report: Detection of the Middle East respiratory syndrome corona virus (MERS-CoV) in nasal secretions of a dead human. J Taibah Univ Med Sci 2018;13:302-4.

4 Schünemann HJ, Moja L. Reviews: Rapid! Rapid! Rapid!... and systematic. Syst Rev 2015;4:4.

5 Ket J, Otten R, VanDusseldorp I. Biomedical information of the Dutch Library Association: coronavirus 2019 (COVID-19) (COVID-19 SARS MERS), 2020. Available: https://blocks.bmi-online.nl/catalog/ 397

6 Thayer KA, Schünemann HJ. Using GRADE to respond to health questions with different levels of urgency. Environ Int 2016;9293:585-9

7 Murad MH, Mustafa RA, Schünemann HJ, et al. Rating the certainty in evidence in the absence of a single estimate of effect. Evid Based Med 2017;22:85-7.

8 Guyatt G, Oxman AD, Akl EA, et al. GRADE guidelines: 1. Introduction-GRADE evidence profiles and summary of findings tables. J Clin Epidemiol 2011;64:383-94.

9 Guyatt GH, Thorlund K, Oxman AD, et al. GRADE guidelines: 13. Preparing summary of findings tables and evidence profiles continuous outcomes. J Clin Epidemiol 2013;66:173-83.

10 Li L, Gu J, Shi X, et al. Biosafety level 3 laboratory for autopsies of patients with severe acute respiratory syndrome: principles, practices, and prospects. Clin Infect Dis 2005;41:815-21.

11 Sriwijitalai W, Wiwanitkit V. COVID-19 in forensic medicine unit personnel: observation from Thailand. J Forensic Leg Med 2020;72:101964.

12 World Health Organization. Infection prevention and control for the safe management of a dead body in the context of COVID-19: WHO, 2020. Available: https://apps.who.int/iris/handle/10665/331538

13 Government of India Ministry of Health \& Family Welfare Directorate General of Health Services. COVID-19: guidelines on dead body management India, 2020. Available: https://www.mohfw.gov.in/ 1584423700568_COVID19GuidelinesonDeadbodymanagement.pdf

14 Ministry of Health and Family Welfare. Novel coronavirus disease 2019 (COVID-19): guidelines on rational use of personal protective equipment Bangladesh, 2020. Available: https://www.mohfw.gov.in/ pdf/GuidelinesonrationaluseofPersonalProtectiveEquipment.pdf

15 Centers for Disease Control and Prevention. Collection and submission of postmortem specimens from deceased persons with known or suspected COVID-19 (interim guidance) US: CDC, 2020. Available: https://www.cdc.gov/coronavirus/2019-ncov/hcp/ guidance-postmortem-specimens.html [Accessed 25 Mar 2020].

16 European Centre for Disease Prevention And Control. Considerations related to the safe handling of bodies of deceased persons with suspected or confirmed COVID-19 Stockholm ECDC 2020. Available: https://www.ecdc.europa.eu/sites/default/files/ documents/COVID-19-safe-handling-of-bodies-or-persons-dyingfrom-COVID19.pdf

17 Centre for Health Protection. Precautions for handling and disposal of dead bodies Hong Kong: Chp, 2020. Available: https://www.chp. gov.hk/files/pdf/grp-guideline-hp-ic-precautions_for_handling_and_ disposal_of_dead_bodies_en.pdf

18 Solna Publich Health Agency. Rekommendationer för hantering AV avliden Med bekräftad COVID-19 Sweden, 2020. Available: https:// 
www.folkhalsomyndigheten.se/contentassets/4a38594abfec482c 9b2b7fbedab7f9e3/omhandertagande.pdf

19 Zhejiang University School of Medicine. Handbook of COVID-19 prevention and treatment China FAZHU, 2020. Available: http://www. zju.edu.cn/english/2020/0323/c19573a1987520/page.htm

20 Ministry of Health Srilanka. Provisional clinical practice guidelines on COVID-19 suspected and confirmed patients Srilanka: MoH, 2020. Available: https://www.president.gov.Ik/provisional-clinical-practiceguidelines-on-covid-19-suspected-and-confirmed-patients/

21 European Centre for Disease Prevention and Control. Infection prevention and control for COVID-19 in healthcare settings United Kingdom: ECDC, 2020. Available: https://www.ecdc.europa.eu/ en/publications-data/infection-prevention-and-control-covid-19healthcare-settings

22 Public Health England. Guidance for first responders and others in close contact with symptomatic people with potential COVID-19 United Kingdom, 2020. Available: https://www.gov.uk/government/ publications/novel-coronavirus-2019-ncov-interim-guidance-forfirst-responders/interim-guidance-for-first-responders-and-othersin-close-contact-with-symptomatic-people-with-potential-2019ncov\#handling-the-deceased

23 Estonian Health Board Ministry of Social Affair. Käitumisjuhend COVID-19 nakkusega või nakkuskahtlusega surnu korral Estonia, 2020. Available: https://www.terviseamet.ee/sites/default/files/ Nakkushaigused/Juhendid/COVID-19/surnukeha_kasitlemise_ pohimotted haiglates.pdf

24 Health Protection Scotland. COVID-19 guidance for infection prevention and control in healthcare settings Scotland, 2020. Available: https://www.hps.scot.nhs.uk/web-resources-container/ covid-19-guidance-for-infection-prevention-and-control-inhealthcare-settings/

25 Centre for Respiratory Diseases and Meningitis and Outbreak Response. Coronavirus disease 2019 (COVID-19) caused by a novel coronavirus (SARS-CoV-2): guidelines for case-finding, diagnosis, management and public health response in South Africa. South Africa, 2020. Available: https://www.nicd.ac.zawpcontent/uploads/2020/03/NICD DoH-COVID-19-Guidelines10March2020_final.pdf
26 Partners in Health. COVID-19 Part II: Clinical Management of COVID-19: PIH;, 2020. Available: https://www.pih.org/sites/default/ files/2020-03/PIH_Guide_COVID_Part_II_Clinical_Management_3_ 21.pdf [Accessed 21 Mar 2020].

27 New South Wales Government. Infection prevention and control COVID-19 (SARS-CoV-2) - residential \& aged care facilities, 2020. Available: http://cec.health.nsw.gov.au/ data/assets/pdf file/0007/ 571543/RACF-Infection-prevention-and-control-COVID-19-Interimguidance-March-2020.pdf [Accessed 12 Mar 2020].

28 New South Wales Government. Infection prevention and control COVID-19 (SARS-CoV-2)-hospital setting, 2020. Available: https:// aci.health.nsw.gov.au/ data/assets/pdf file/0003/568506/Infectioncontrol-nCoV-2019-Hospital-Setting-V2-.pdf [Accessed 12 Mar 2020].

29 The Royal College of Pathologists. Autopsy practice relating to possible cases of COVID-19 (2019-nCov, novel coronavirus from China 2019/2020) (Briefing). Available: https://www.rcpath.org/ uploads/assets/d5e28baf-5789-4b0f-acecfe370eee6223/fe8fa85af004-4a0c-81ee4b2b9cd12cbf/Briefing-on-COVID-19-autopsy-Feb2020.pdf [Accessed 24 Mar 2020].

30 Agarwal A, Nagi N, Chatterjee P, et al. Guidance for building a dedicated health facility to contain the spread of the 2019 novel coronavirus outbreak. Indian J Med Res 2020. doi:10.4103/ijmr. IJMR_518_20. [Epub ahead of print: 16 Mar 2020].

31 Chinese Medical Association Association of Pathologists. [Provisional guidelines on autopsy practice for deaths associated with COVID-19]. Chin J Pathol 2020.

32 Mao Dan-mi ZN, Da Z, Jia-cheng, Zhao Qian-hao LE, et al. [Guide to the forensic pathology practice on death cases related to corona virus disease 2019 (COVID-19)]. J Forensic Med 2020;36.

33 Sundhedsstyrelsen. Retningslinjer for håndtering AF COVID-19 | sundhedsvæsenet: guidelines for handling COVID-19 in health care Denmark, 2020. Available: https://www.sst.dk/-/media/Udgivelser/ 2020/Corona/Retningslinjer-marts/Retningslinje-COVID-19.ashx?la= da\&hash=84942068EA39162A0B8E26A6AAFD6CC256276F14

34 Helsedirektoratet. Koronavirus - beslutninger OG anbefalinger. Norway, 2020. Available: https://www.helsedirektoratet.no/veiledere/ koronavirus 